\title{
Microstructural defect properties of InGaN/GaN blue light emitting diode structures
}

\author{
Y. Baş $\cdot$ P. Demirel $\cdot$ N. Akın $\cdot$ C. Başköse $\cdot$ \\ Y. Özen · B. Kınacı • M. K. Öztürk · \\ S. Özçelik • E. Özbay
}

Received: 20 March 2014/Accepted: 17 June 2014/Published online: 28 June 2014

(C) Springer Science+Business Media New York 2014

\begin{abstract}
In this paper, we study structural and morphological properties of metal-organic chemical vapour deposition-grown InGaN/GaN light emitting diode (LED) structures with different indium (In) content by means of high-resolution X-ray diffraction, atomic force microscopy (AFM), Fourier transform infrared spectroscopy (FTIR), photoluminescence (PL) and current-voltage characteristic (I-V). We have found out that the tilt and twist angles, lateral and vertical coherence lengths of mosaic blocks, grain size, screw and edge dislocation densities of $\mathrm{GaN}$ and InGaN layers, and surface roughness monotonically vary with In content. Mosaic defects obtained due to temperature using reciprocal lattice space map has revealed optimized growth temperature for active InGaN layer of MQW LED. It has been observed in this growth temperature that according to AFM result, LED structure has high crystal dimension, and is rough whereas according to PL and FTIR results, bandgap energy shifted to blue, and energy peak half-width decreased at high values. According to I-V measurements, it was observed that LED reacted against
\end{abstract}

\footnotetext{
Y. Baş $(\bowtie)$

National Boron Research Institute, 06520 Ankara, Turkey

e-mail: yunus@boren.gov.tr

P. Demirel · E. Özbay

Department of Physics, Department of Electrical and Electronics Engineering, Nanotechnology Research Center, Bilkent, 06800 Ankara, Turkey

N. Akın · C. Başköse · Y. Özen · M. K. Öztürk · S. Özçelik Department of Physics, Gazi Photonic Research Center, Teknikokullar, 06500 Ankara, Turkey

B. Kınac1

Department of Physics, Faculty of Science, Istanbul University, Vezneciler, 34134 Istanbul, Turkey
}

light at optimized temperature. In conclusion, we have seen that InGaN MQW structure's structural, optical and electrical results supported one another.

\section{Introduction}

The latest developments in light emitting diode (LED) technology necessitate closely following the innovations in this field with regard to both commerce and science. LED is widely used in a number of fields such as indicators, screens and panels. The white light seen on LED cannot be directly obtained but rather obtained through either mixing three colours (red, blue and green) or phosphor-coating of InGaN LED which emits blue light [1]. Naturally, it is possible to ensure luminescence, long-life and low energy requirement through developing InGaN blue LEDs. InGaN LEDs are preferred for their strong hexagonal material which is resistant to high temperatures, frequency and high pressure values. However, defects such as dislocation, tilt, deflection, and twist or mosaic coalescence occur due to the high lattice mismatch between a conventional substrate such as sapphire or silicon, and InGaN epitaxial layer. For instance, it causes cracks in dislocation layers. As widely known, volumetric or linear defects are more dominant in the structure.

In order to eliminate volumetric or linear defects, usually GaN buffer and plane layers are grown. This buffer and plane layers are grown between InGaN and sapphire before InGaN/GaN multiple layer with a view to eliminating lattice mismatch. In this way, structural properties improve thanks to the formation of crystal structure which leads to improvement in electrical and optical properties. Also, the InGaN active layer in these LEDs include a large number of threading dislocations (TDs), from $1 \times 10^{8}$ to 
$1 \times 10^{12} \mathrm{~cm}^{-2}$, which originate from the interface between $\mathrm{GaN}$ and the sapphire substrate due to a large lattice mismatch of $15 \%[2,3]$. It is considered that the TDs are formed as a result of a complex set of interactions that include energy, nucleation density and island coalescence [4]. In spite of this large number of dislocations, the efficiency of InGaN-based LEDS and LDs is much greater than that of the conventional III-V compound semiconductor-based LEDs and LDs. In many conventional optoelectronic devices, device performance has been limited by both point defects and structural defects in these materials. However, these recent reports suggest that III-V nitridebased devices are less sensitive to dislocations than conventional semiconductors.

In this study, three different LED samples with InGaN multiple quantum well were grown. In these samples, all parameters except InGaN growth temperature were structurally maintained fixed. When analyzing the samples, we carried out reciprocal lattice space mapping of high-resolution symmetrical-asymmetrical planes in order to identify structural properties of crystallized layers. With the power of this method, we were able to observe the defects in the structure better. In literature, it is quite frequently reported that strain and indium (In) composition ratio of widespread errors for $\operatorname{In}_{\mathrm{x}} \mathrm{Ga}_{1-\mathrm{x}} \mathrm{N}$ cannot be distinguished between one another $[5,6]$. We therefore used cubic equation in this study in order to distinguish between strain and In rates [5]. We analyzed morphological structure of the surface using atomic force microscopy (AFM) images. We identified forbidden energy band gap from photoluminescence (PL) measurements; InGaN structure's molecular oscillation bands from Fourier transform infrared spectroscopy (FTIR) spectrum; and LED's reaction to light from $\mathrm{I}-\mathrm{V}$ measurements.

\section{Experimental details}

\subsection{Material preparation}

We grew five-period InGaN multiple quantum well by metal-organic chemical vapour deposition (MOCVD) technique. During the growth, the pressure was fixed at 200 mbar. InGaN/GaN MQW layers were grown over c-surfaced (0001) sapphire $\left(\mathrm{Al}_{2} \mathrm{O}_{3}\right)$ substrate. Before growing the layers, the sapphire substrates were cleaned in $\mathrm{H}_{2}$ atmospheric environment at $1,100{ }^{\circ} \mathrm{C}$. At first, GaN nucleation layer with a thickness of $25 \mathrm{~nm}$ was grown at $500{ }^{\circ} \mathrm{C}$. Then, GaN plane layer was grown at $1,020{ }^{\circ} \mathrm{C}$. Two n-type GaN contact layers were grown throughout 35 and $20 \mathrm{~min}$ at $1,030^{\circ} \mathrm{C}$ adjusting Trimethylgallium (TmGa) flux ratio to $23 \mathrm{sccm}$. For Mg-compounded two p-contact layers, TmAl flux ratio was identified as

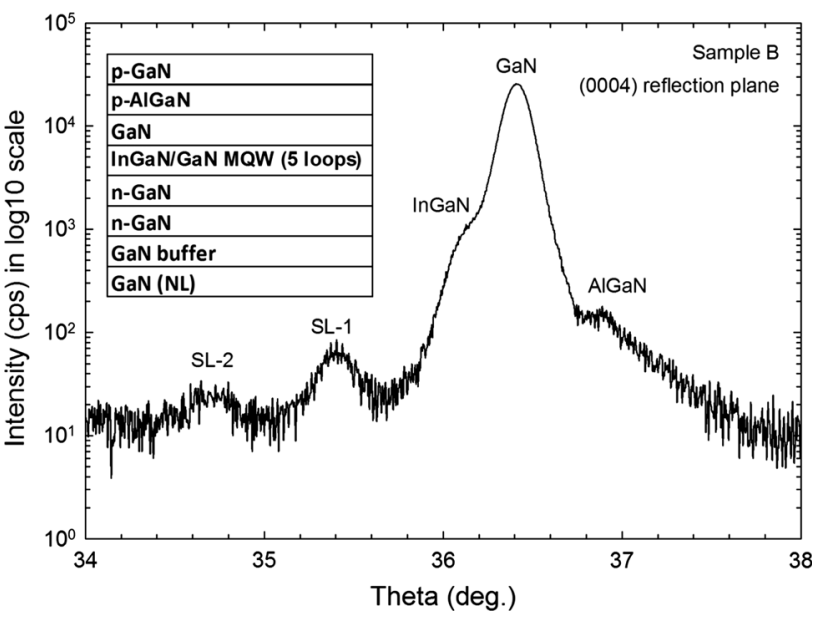

Fig. 1 The omega or theta plot of the (0004) miller plane's HRXRD reflection, and LED structure (Sample B)

$15 \mathrm{sccm}$; and TmGa flux ratio and growth temperatures for $\mathrm{AlGaN}$ and $\mathrm{GaN}$ were identified to be $9 \mathrm{sccm}, 1,085^{\circ} \mathrm{C}$, and $14 \mathrm{sccm}, 1,010{ }^{\circ} \mathrm{C}$, respectively. Active layer was grown between $\mathrm{p}$ and $\mathrm{n}$ contacts as a multiple-quantum well with 5-layer InGaN/GaN periods. In each period, In$\mathrm{GaN}$ and $\mathrm{GaN}$ were grown for 1.5 and 6.5 min with $\mathrm{Ga}$ and In flux rates of $140 \mathrm{sccm}$, respectively. For GaN and In$\mathrm{GaN}, \mathrm{NH}_{3}$ flux ratio was calibrated as 1,300 and $5,200 \mathrm{sccm}$, respectively. All other properties except period temperature were maintained fixed for the three samples and their growth temperatures for active layer are 650 , 667 and $700{ }^{\circ} \mathrm{C}$, respectively.

In order to carry out $\mathrm{I}-\mathrm{V}$ analysis of the samples with $\mathrm{n}$ - $\mathrm{p}$ contact materials, for $\mathrm{n}$-metal, $\mathrm{Ti}-\mathrm{Al}$ contacts were formed at 100 and 1,000 $\AA$ thickness, respectively; and for p-metal, $\mathrm{Ni}-\mathrm{Al}$ contacts were formed at 200 and 2,000 thickness, respectively. Figure 1 illustrates overall schematic view of grown LED structures. The grown LED structure contained within the inset of Fig. 1 is similarly confirmed by HRXRD omega/2Theta measurement which has the same shape. Satellite peaks SL-1 and SL-2 are composed of interference of XRD peak reflections from $\mathrm{GaN}$ and InGaN layers, and used to find MQW thickness. Finger peak formation among satellite peaks is weak. As the interlayer roughness increases, the roughness-related XRD interferences are distorted.

\subsection{Material characterization}

D8-Discovery XRD device $\mathrm{CuK} \alpha_{1}$ tube with a wavelength of $1.5406 \AA$ as the supply was used for high-resolution $\mathrm{X}$-ray diffraction (HRXRD) measurements. For high resolution, monochromator with 4-crystal Ge (220) crystal was also used. In order to provide for diffraction requirement from symmetrical-asymmetrical planes, there are $\mathrm{x}$, 
y, z, $\Phi$ and $\xi$ axes other than $\theta$ and $2 \theta$. For reciprocal lattice space, $\theta, 2 \theta, \Phi$ and $\xi$ axes were used. The samples were attached to the device through vacuum. Moreover, the whole filming lasted approximately for $112 \mathrm{~h}$ with average $7 \mathrm{~h}$ of filming for each measurement along with that of the axes which optimize reciprocal lattice space.

Morphological properties were characterized with high performance atomic force microscope (Nano Magnetics Instruments Ltd., Oxford, UK) using dynamic mode scanning. PL measurements were taken by using Jobin-Yvon Florong-550 PL system with a 50-mW $\mathrm{He}-\mathrm{Cd}$ laser $(\lambda=325 \mathrm{~nm})$ as excitation light source at room temperature. The current voltage characteristics were performed using Keithley 4,200 source-meter, and Oriel Soll A class AAA solar simulator. For the FTIR measurement, a Bruker vertex 80 IR spectrometer, with a mid-IR region along with a Germanium attenuated total reflectors (ATR) were used.

\section{Results and discussion}

Figure 2 illustrates only reciprocal space map of (0002) and (10-15) planes of high-resolution samples. On these figures, $l$ miller indexes for $\mathrm{GaN}, \mathrm{InGaN}$ and $\mathrm{AlGaN}$ were observed to be approximately $2.00,1.97$ and 2.25 on the symmetrical plane on direction 1 [001], respectively. Furthermore, 1 miller indexes for $\mathrm{GaN}$, InGaN and AlGaN were observed to be approximately 5.33, 5.28 and 5.35 on asymmetrical plane (10-15), respectively. Asymmetrical peaks were scanned with extensive offset values. These offsets were then eliminated according to the universal values of GaN. While symmetrical peaks are dominant on (0002) plane, satellite peaks formed due to the interference caused by differences between $\mathrm{GaN}$ and InGaN intensity appear well-separated just below the InGaN peak. Thickness calculation is possible through these satellite peak separations. For thickness calculation, basically $T=$ $\lambda /(2 * \Delta \theta * \cos \theta)$ formula was used [6]. $\lambda$ is wavelength of X-ray source; and $\Delta \theta$ is satellite peak separation; and $\theta$ is Bragg angle of the plane. Quantum well thicknesses are given in the last column of Table 1 by sequence depending on the temperature. It is observed that depending on the increase in temperature, barrier and InGaN quantum well thickness decreases.

Figure 3 shows half-width of peak heights depending on temperature for samples A, B and C of left y axes, and for
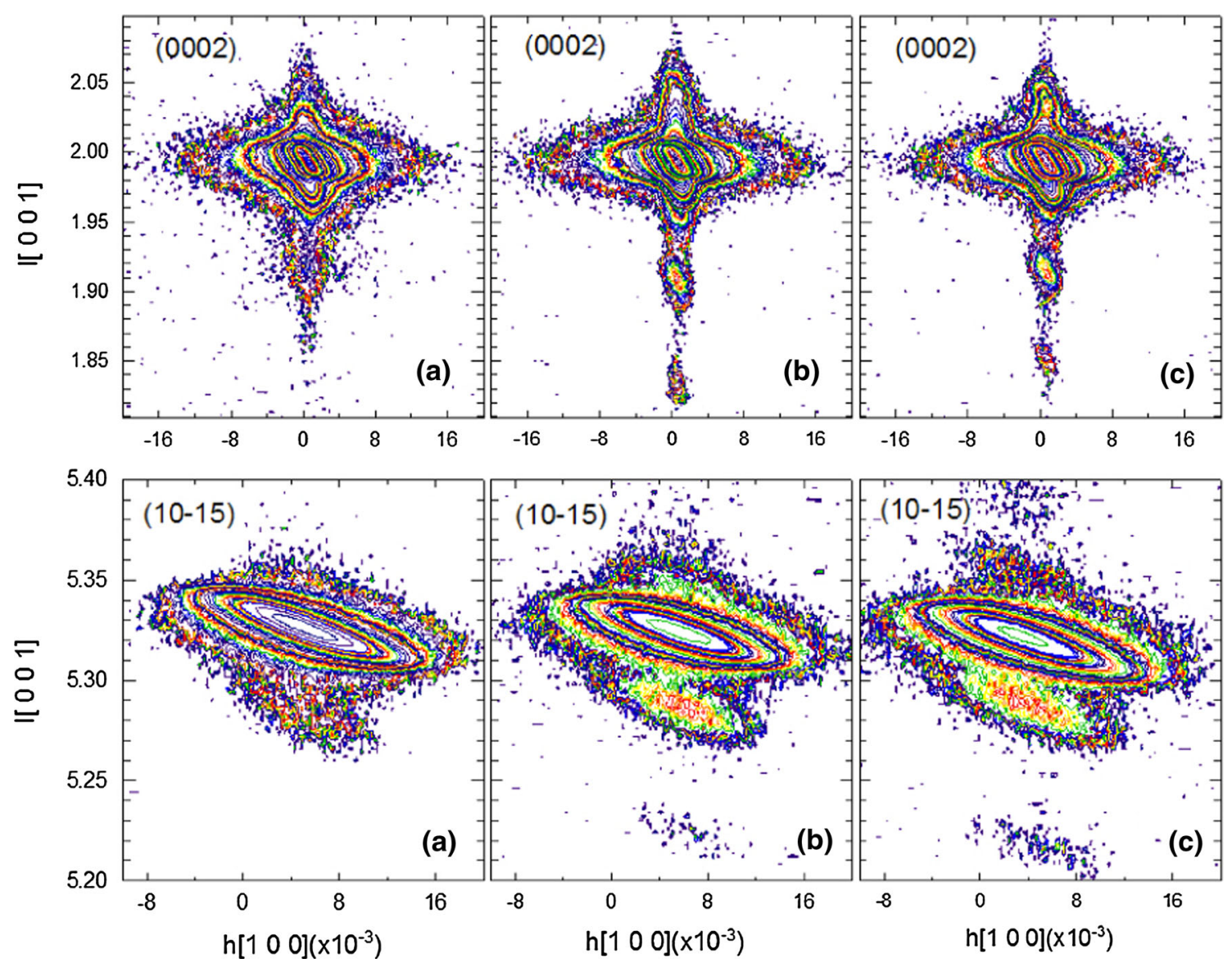

Fig. 2 Reciprocal space mapping of the symmetric (0002) and asymmetric (10-15) planes for all samples 
Table 1 The InGaN growth temperature, In alloy ration, $c$ and a- strain values, and MQW thicknesses

\begin{tabular}{lllccc}
\hline Samples & $\begin{array}{l}\text { Temp. } \\
\left({ }^{\circ} \mathrm{C}\right)\end{array}$ & $\begin{array}{l}\text { In content } \\
(\%)\end{array}$ & $\begin{array}{l}\text { Strain c } \\
\left(\times 10^{-4}\right)\end{array}$ & $\begin{array}{l}\text { Strain a } \\
\left(\times 10^{-3}\right)\end{array}$ & $\begin{array}{l}\mathrm{L} \\
(\mathrm{nm})\end{array}$ \\
\hline $\mathrm{A}$ & 650 & 10.87 & 7.09 & -2.48 & 13.87 \\
$\mathrm{~B}$ & 667 & 9.01 & 10.90 & -3.83 & 12.58 \\
$\mathrm{C}$ & 700 & 7.51 & -2.86 & 1.00 & 10.39 \\
\hline
\end{tabular}

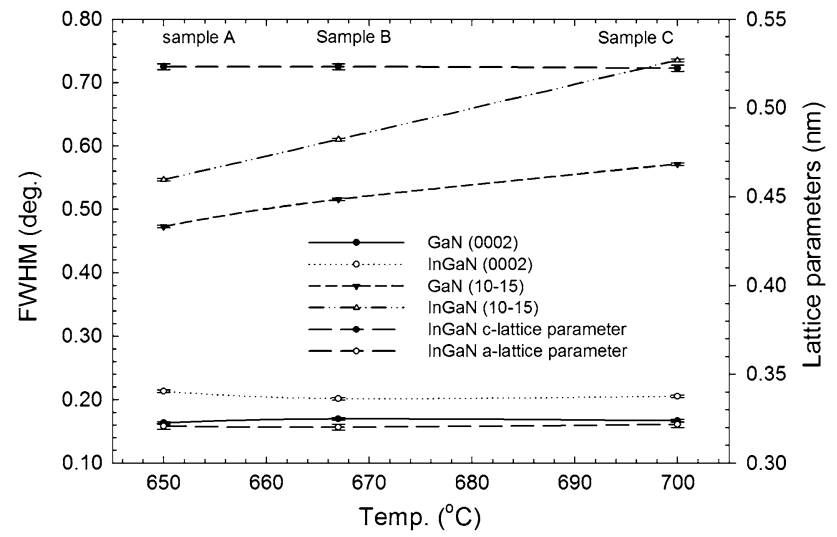

Fig. 3 FWHM values and InGaN lattice parameters of the (0002) and (10-15) planes for GaN and InGaN layers in three samples as depending on growth temperature

symmetrical (0002) and asymmetrical (10-15) planes of $\mathrm{GaN}$ and $\mathrm{InGaN}$ layers. At increasing temperatures, FWHM of GaN is relatively lower than InGaN's, and while (0002)'s FWHM values increase and decrease, (10-15)'s FWHM values tend to increase. InGaN's peak half-widths indicate decrease and increase at low values for (0002) while (10-15) indicates increase for GaN layer at a higher slope compared to the value of (0002). Moreover, right axis of Fig. 3 shows c and a-lattice parameters of InGaN layer by temperature. While c-lattice parameter decreases by $0.523 \mathrm{~nm}$ at lower values due to the temperature, a-lattice parameter first indicates an average decrease around $0.3205 \mathrm{~nm}$ and an increase afterwards.

Percentage of In rate was accurately identified from the $\mathrm{GaN}$ and $\mathrm{InGaN}$ peak separation on reciprocal lattice space map. Cubic equation method is a significant way for distinguishing between these In alloy rates and strain values [5]. Cubic equation is found via $\mathrm{x}$, obtained from Vegard's law, and lattice and Poisson's equations, and given through following equation.

$P x^{3}+Q x^{2}+R x+S=0$

Here, P, Q, R and S coefficients, and lattice and elastic constraints for $\mathrm{GaN}$ and $\mathrm{InN}$ in the equations are given below.

$$
\begin{aligned}
P= & (v(A)-v(B))\left(\left(a_{0}(A)\right)-a_{0}(B)\right)\left(c_{0}(A)-c_{0}(B)\right) \\
Q= & (1+v(B))\left(a_{0}(A)-a_{0}(B)\right)\left(c_{0}(A)-c_{0}(B)\right) \\
& +(v(A)-v(B))\left[\left(a_{0}(A)-a_{0}(B)\right) c_{0}(B)\right. \\
& \left.+\left(a_{0}(B)-a(L)\right)\left(c_{0}(A)-c_{0}(B)\right)\right] \\
R= & \left(a_{0}(A)-a_{0}(B)\right)\left[(1+v(B)) c_{0}(B)-c(L)\right] \\
& +\left(c_{0}(A)-c_{0}(B)\right)\left[(1+v(B)) a_{0}(B)-v(B) a(L)\right] \\
& +(v(A)-v(B))\left(a_{0}(B)-a(L)\right) c_{0}(B) \\
S= & (1+v(B)) a_{0}(B)-c_{0}(B)-v(B) a(L) c_{0}(B) \\
& -a_{0}(B) c(L)
\end{aligned}
$$

Constraints used in this equation for $\mathrm{GaN}$ and $\mathrm{InN}$ are givenas $c_{0}^{\text {GaN }}=0.51850, a_{0}^{\text {GaN }}=0.31892, c_{0}^{I n N}=0.57033$, $a_{0}^{I n N}=0.35387 \mathrm{~nm}$, respectively; and for $\mathrm{GaN}$ as $C_{13}=103 \mathrm{GPa}, C_{33}=405 \mathrm{GPa}$; and for $\mathrm{InN}$ as $C_{13}=$ $92 \mathrm{GPa}$ and $C_{33}=224 \mathrm{GPa}$ [6].

This equation has three real roots. But only one of these carries physical meaning. The value of $\mathrm{x}$ rate varies between 0 and 1 . Obtained In alloy values of $x$ are provided as percentage in third column on Table 1 . It can be seen on this table that In-content value indicates decreasing behaviour with increasing temperature. After calculating right In value, vertical and parallel strains are calculated with much more accurate values. Reciprocal lattice space mapping plays a significant role in calculation of these accurate values. Peak dislocations or offsets that occur in standard measurements are thus eliminated by means of reciprocal lattice space map. Calculated strain values are given in columns 4 and 5 on Table 1 depending on the temperature. The calculation of strain was done according to InGaN's universal values and $\Delta x / x_{0}$ equation where $\Delta x=x-x_{0}$ and $x, x_{0}$ are strained and non-strained (universal) lattice parameters, respectively. Universal values of InGaN were calculated using $\mathrm{InN}$ and $\mathrm{GaN}$ lattice parameters. With the increasing temperature, obtained strain values exhibit an increasing and decreasing behaviour in c-strain $\left(\times 10^{-4}\right)$, and a decreasing and increasing behaviour in a-strain $\left(\times 10^{-3}\right)$ similar to the behaviour of In. Nitrided materials, though they grow as crystallized, have often bear mosaic structure defects. These are defects such as dots, lines and volumetric defects caused by formation of In droplets, tensions arising out of rapid cooling of $\mathrm{Al}$ layers, lattice mismatch among layers and impurities [7].

In the radial-scan direction of the symmetric reflections, a vertical CL normal to the substrate surface and a heterogeneous strain along the c-axis causes broadening of the Bragg reflections. For the symmetric and asymmetric scans, the incoming and outgoing wave vectors are within the same polar or $\mathrm{z}$ axis containing the scattering plane. In the case of the symmetric diffraction geometry, the lateral 
Table 2 HRXRD and AFM results for samples A, B, and C

\begin{tabular}{|c|c|c|c|c|c|c|c|}
\hline $\begin{array}{l}\text { Samples } \\
(\mathrm{GaN} / \mathrm{InGaN}) \\
\text { Temp./In content } \\
\left({ }^{\circ} \mathrm{C} / \%\right)\end{array}$ & $\begin{array}{l}\text { Heterogenous } \\
\text { strain }\left(\times 10^{-4}\right)\end{array}$ & $\begin{array}{l}\text { Surface } \\
\text { RMS } \\
(\mathrm{nm})\end{array}$ & $\begin{array}{l}\text { Late. CL } \\
(\mathrm{nm})\end{array}$ & $\begin{array}{l}\text { Verti. } \\
\text { CL } \\
(\mathrm{nm})\end{array}$ & $\begin{array}{l}\text { Tilt angle } \\
\left(\times 10^{-2}\right) \\
\text { [deg.] }\end{array}$ & $\begin{array}{l}\text { ScrewTDD }\left(\times 10^{7} /\right. \\
\left.10^{8} \times 10^{7} / 10^{8}\right) \\
{\left[\mathrm{cm}^{-2}\right]}\end{array}$ & $\begin{array}{l}\text { Edge TDD } \\
\left(\times 10^{8} / 10^{9} \times 10^{8} / 10^{9}\right) \\
{\left[\mathrm{cm}^{-2}\right]}\end{array}$ \\
\hline A650/10.87 & $-5.88 /-2.02$ & 2.07 & $64,591 / 429$ & $195 / 175$ & $0.29 / 0.82$ & $\begin{array}{l}2.18 / 1.78 \\
33.64 / 5.69\end{array}$ & $\begin{array}{l}109.82 / 336.91 \\
74.82 / 8.57\end{array}$ \\
\hline B667/9.01 & $-6.15 /-7.06$ & 9.55 & $1,852,333 / 5,313$ & $187 / 162$ & $0.30 / 0.37$ & $\begin{array}{l}2.34 / 0.37 \\
36.19 / 5.09\end{array}$ & $\begin{array}{l}3.42 / 189.57 \\
89.01 / 10.86\end{array}$ \\
\hline C700/7.51 & $-5.51 /-6.38$ & 2.31 & $3,918 / 2,392$ & $196 / 159$ & $0.34 / 0.44$ & $\begin{array}{l}3.00 / 0.52 \\
34.96 / 5.28\end{array}$ & $\begin{array}{l}1,895.4 / 456.10 \\
109.20 / 15.72\end{array}$ \\
\hline
\end{tabular}

CL and tilt of the mosaic blocks result in the broadening of the rocking curves perpendicular to the polar axis [8]. The contribution of the two effects causes a linear dependence on the broadening of the reflection order, which is used to separate individual contributions. For this purpose, a Williamson-Hall (W-H) plot, which is a plot of the FWHM of the rocking curve as a function of the reflections order, i.e., FWHM $(\sin \theta) / \lambda$ plotted against $(\sin \theta) / \lambda$ for each reflection wherein the plotted curve is fitted with a straight line, can be used $[9,10]$. FWHM is the integral width of the measured profile, and $\lambda$ and $\theta$ are $\mathrm{X}$-ray wavelength and incident angle of the X-rays. The tilt angle is then obtained from the slope of the linear dependence and lateral CL, and $\mathrm{L}_{\|}$follows from the inverse of the point of interception with the ordinate. Obtained lateral CLs and tilt angles for every two GaN and AIN layers are given in the fifth and seventh columns of Table 2. At increasing In content values, when the tilt angles for GaN layer increase, those of InGaN layers first increase as well and decrease afterwards. At the same time, when the lateral CLs for GaN layers increase sharply and then decrease dramatically, those of InGaN layers show a similar behaviour to that of $\mathrm{GaN}$. Additionally, the mosaic block dimensions parallel to the surface for $\mathrm{GaN}$ layers are bigger than those of $\mathrm{InGaN}$ layers. The reason behind this can be the rapid cooling of layers.

In the $\mathrm{W}-\mathrm{H}$ plot $[8,9], \beta_{2 \theta}(\cos \theta) / \lambda$ is plotted against $(\sin \theta) / \lambda$ for each reflection and again fitted by a straight line. From the $y$-intersection $y_{0}$, the vertical correlation length $\mathrm{L}_{\perp}$ can be estimated $\left(L_{\perp}=0.9 /\left(2 y_{0}\right)\right.$, and the strain $\varepsilon_{\perp}$ is directly obtained from the slope of the line, which is $4 \varepsilon_{\perp}$. Obtained vertical CLs and heterogeneous strains for the $\mathrm{GaN}$ and $\mathrm{InGaN}$ layers are given in the second and fifth columns of Table 2. Both of heterogeneous strain values and vertical values first decrease and then increase at increasing temperatures as illustrated in second and fifth columns of Table 2. On the other hand, heterogeneous strain values for InGaN are compatible with $\mathrm{GaN}$, and its vertical values constantly tend to decrease at increasing temperatures.
It is well known that hexagonal structured nitrided layers grown on a lattice mismatched substrate, such as $\mathrm{Al}_{2} \mathrm{O}_{3}, \mathrm{SiC}$ and $\mathrm{Si}$, exhibit high TDD. In this study, InGaN/ GaN epilayers were grown on sapphire substrate which exhibit high TDD. There are three main types of TDs in these layers [8, 11]; the pure edge type of TD with a Burgers vector of the $\langle a\rangle$ direction, pure screw type TD with Burgers vector of $\langle c\rangle$ direction, and mixed TD with a vector of the $\langle c+a\rangle$ direction. This study used two methods to observe the trend that comes from the crystallized case and mosaic tilt effect. Edge $\left(\mathrm{D}_{\text {edge }}\right)$ and screw $\left(\mathrm{D}_{\text {screw }}\right)$ type TDD in the epitaxial layers can be calculated from the equation given below [9, 12-15].

$D_{\text {screw }}=\frac{\beta_{(0002)}^{2}}{9 b_{\text {screw }}^{2}}, D_{\text {edge }}=\frac{\beta_{(10-12)}^{2}}{9 b_{\text {edge }}^{2}}$

where $\beta$ is FWHM value of the rocking curve, and $b$ is Burgers vector length $\quad\left(b_{\text {screw }}=0.5185 \mathrm{~nm}\right.$, $\mathrm{b}_{\text {edge }}=0.3189 \mathrm{~nm}$ for $\mathrm{GaN}$ and $\mathrm{b}_{\text {screw }}=0.5198 \mathrm{~nm}$, $\mathrm{b}_{\text {edge }}=0.3417 \mathrm{~nm}$ for InGaN). Calculated edge and screw type TDDs of the GaN and InGaN layers are listed in the last two columns of Table 2.

With increasing temperature, screw dislocations of $\mathrm{GaN}$ layer shows an increasing character while edge dislocation shows a behaviour that first decreases and then increases. On the other hand, for InGaN layer, both screw and edge dislocation first tends to decrease and then to increase. Growth conditions of GaN layer in MOCVD are optimized much better than InGaN's. Therefore, it was concluded that screw and edge TDDs of InGaN layers are larger as per the first method.

Another method for edge and screw TDDs is based on both tilt angle and lateral coherence lengths (CLs) with Burgers vectors. All types of TDs are correlated with CLs, tilt angle and twist angle. As reported by Metzger et al. [8], for (0002)-oriented GaN epitaxial films, the mean twist angle is monotonically related to the edge-type TDD with a Burgers vector of $b=1 / 3(11-20)$ while the mean tilt angle is monotonically related to, and can be converted 
into, screw type TDD with a Burgers vector of $\mathrm{b}=<0001>$ [7]. Also, edge type TDs with a Burgers vector of $b=1 / 3(11-20)$ can reconcile an azimuthally rotation of crystallites around the normal of the surface. Edge-type TDD can be calculated from measured twist angle $\alpha_{\text {twist }}$. Edge TDDs are piled up in small angle grain boundaries. Screw TDD and edge TDD can be calculated from following equations [16-19]

$N_{s c}=\frac{\alpha_{\text {tilt }}^{2}}{4.35\left|b_{s c}\right|^{2}} \quad, N_{E}=\frac{\alpha_{\phi}}{2.1\left|b_{E}\right| L_{\|}}$

where $\alpha_{\text {tilt }}$ is the tilt angle which is a mosaic defect, and $b_{\text {screw }}$ is Burgers vector length. Also, $\alpha_{\phi}$ is the peak broadening of asymmetric planes, and $b_{E}$ is Burgers vector length, and $L_{\|}$is lateral CL. In the last two columns of Table 2, screw TDDs calculated from second method in GaN buffer layers of samples A, B and C first increase, and then decrease with increasing growth temperature or decreasing In content values.

Screw TDDs for InGaN layer, on the other hand, first decreased and then increased unlike GaN. Edge TDDs similarly exhibit an increasing behavior parallel to the increasing growth temperature for both $\mathrm{GaN}$ and $\mathrm{InGaN}$ layers.

Dislocation motion leads to plastic deformation. Further plastic movements even result in cracks. This case does not occur with nucleation layer. In an edge TD, localized lattice distortions exist along the end of an extra half-plane of atoms. When edge TD moves in response to a shear stress, the motion of a screw TD is also a resultant of a shear stress or a shear distortion. The crystals are separated by a thin non-crystalline region which is the characteristic structure of a large angle grain boundary. Atomic disorders at the boundary cause discontinuity in slip planes. Hence, TDs are stopped by a grain boundary and pile up against it. The smaller the grain size is, the more frequent the pile up of TD gets [9, 14].

As illustrated on Table 2 in the last two columns, screw TDDs for GaN layer show constant increase for the first method while, for the second method, they show an initial increase followed by a decrease. Edge TDDs for GaN layer show an initial decrease followed by an increase as per the first method while they show constant increase as per the second method. Screw TDDs for InGaN layer show an initial decrease followed by increase both for the first and second method whereas Edge TDDs for InGaN layer show an initial decrease followed by increase as per first method, and constant increase as per second method.

Decreasing and increasing behaviour in In content resulting from increasing growth temperature and the decrease occurring in the In content as a result has indicated optimized situation for sample B. An overview of Table 2 would indicate dominant behaviour of lateral (a) 2D 3D

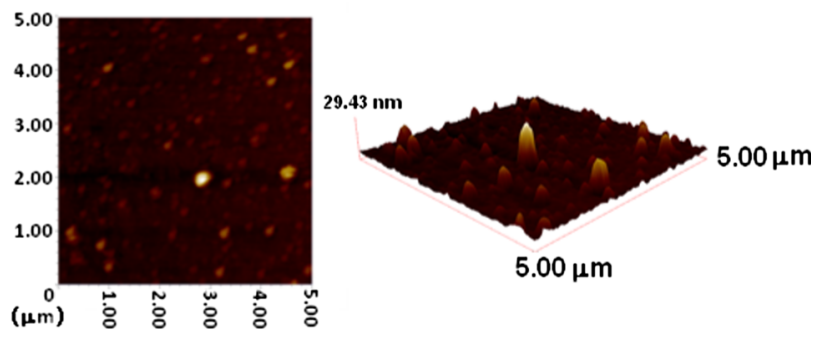

(b)

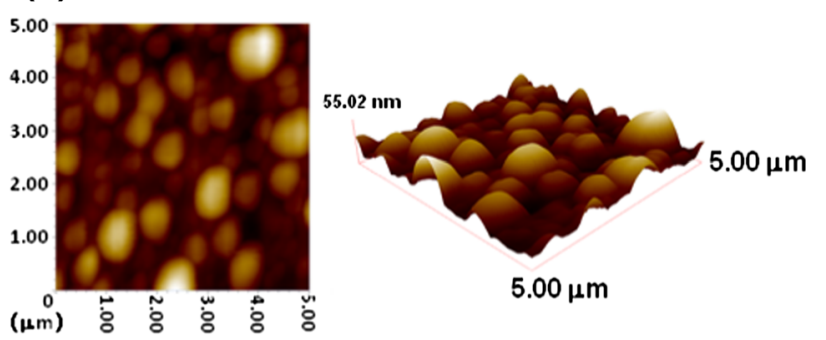

(c)

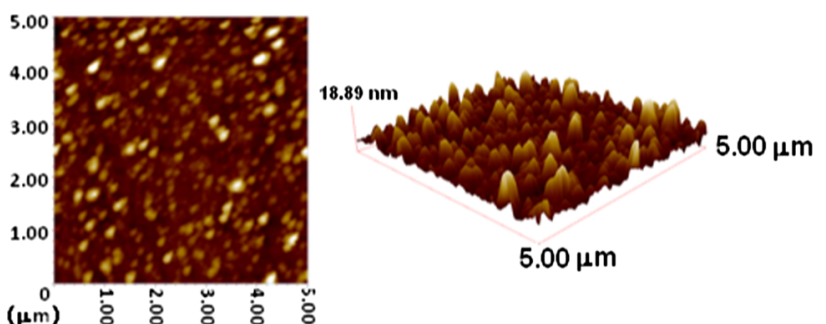

Fig. 4 2D and 3D AFM images of InGaN/GaN blue LED structures with various growth temperature; a $650{ }^{\circ} \mathrm{C}$, b $667{ }^{\circ} \mathrm{C}$ and c $700{ }^{\circ} \mathrm{C}$. The scan area is $5 \times 5 \mu \mathrm{m}^{2}$ in the all images

coherent length and edge TDD defects in two structural defects compared to other defects. With the increase in lateral coherent length, edge dislocation has decreased. Accordingly, heterogeneous strain, tilt, screw type dislocation, and even vertical lateral coherent length, which constantly increases at minimal values, supports the optimized state in sample B.

Figure 4 shows two-dimensional (2D) and threedimensional (3D) AFM images with $5 \times 5 \mu^{2}$ scan area of the samples $\mathrm{A}, \mathrm{B}$ and $\mathrm{C}$ at different growth temperature which corresponds to 650,667 and $700{ }^{\circ} \mathrm{C}$, respectively. The surface of sample B looks quite well compared to the other two samples. Sample B has the most uniform surface morphology while sample A has the least. Root mean square (RMS) values of the surface roughness of all samples were measured to be $2.07,9.55$ and $2.31 \mathrm{~nm}$, respectively. The surface of the sample $\mathrm{B}$ became rough because of the coarse grains. The sample A and sample $\mathrm{C}$ did not have any cylindrical islands compared the sample B. Similar MOCVD-grown GaN structure results were also 


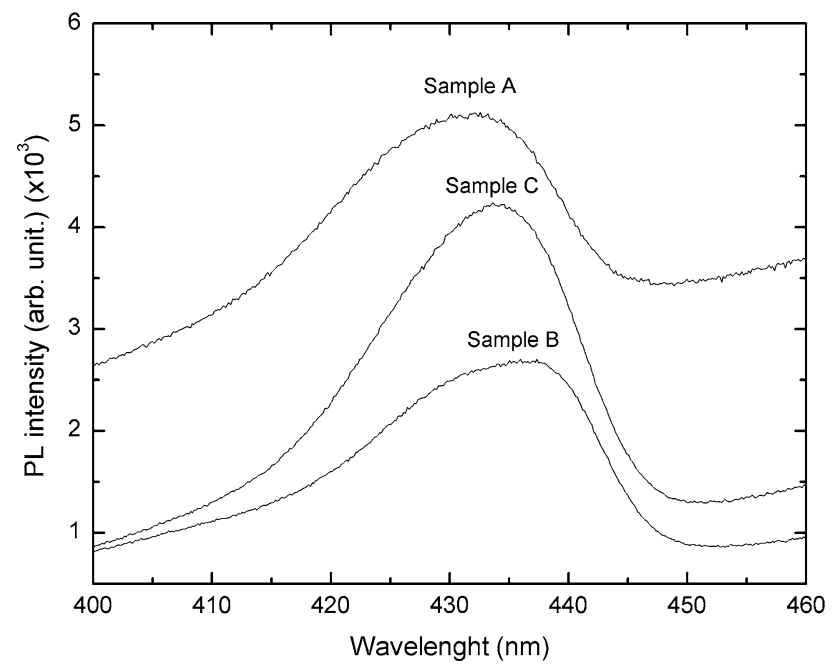

Fig. 5 PL spectra of the InGaN/GaN blue LED structures on sapphire substrate

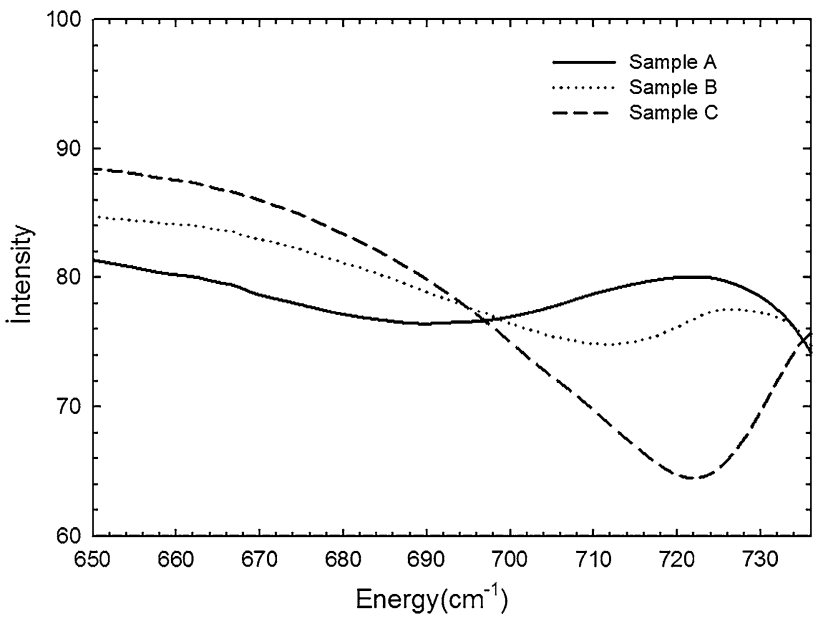

Fig. 6 FTIR vibration spectrum of the InGaN active layer

Table 3 The PL bandgap and FTIR vibration energy peak positions and FWHM values in the active layer of the InGaN/GaN blue LED structures on sapphire substrate

\begin{tabular}{lllll}
\hline & $\begin{array}{l}\text { Bandgap } \\
(\mathrm{nm})(\mathrm{eV})\end{array}$ & $\begin{array}{l}\text { FWHM } \\
(\mathrm{nm})\end{array}$ & $\begin{array}{l}\text { Vibration } \\
\text { energy }\left(\mathrm{cm}^{-1}\right)\end{array}$ & $\begin{array}{l}\text { FWHM } \\
\left(\mathrm{cm}^{-1}\right)\end{array}$ \\
\hline A & $430.12(2.88)$ & 20.80 & 690 & 34 \\
B & $436.43(2.84)$ & 21.20 & 712 & 19 \\
C & $433.82(2.86)$ & 19.70 & 722 & 22 \\
\hline
\end{tabular}

reported in literature [20]. The change of RMS values is associated with increase of grain size which is consistent with the XRD results. The AFM results indicate that surface morphology of the InGaN/GaN blue LED structures is largely affected by growth temperature. Suitable growth temperature (around $667^{\circ} \mathrm{C}$ ) can lead to the improvement
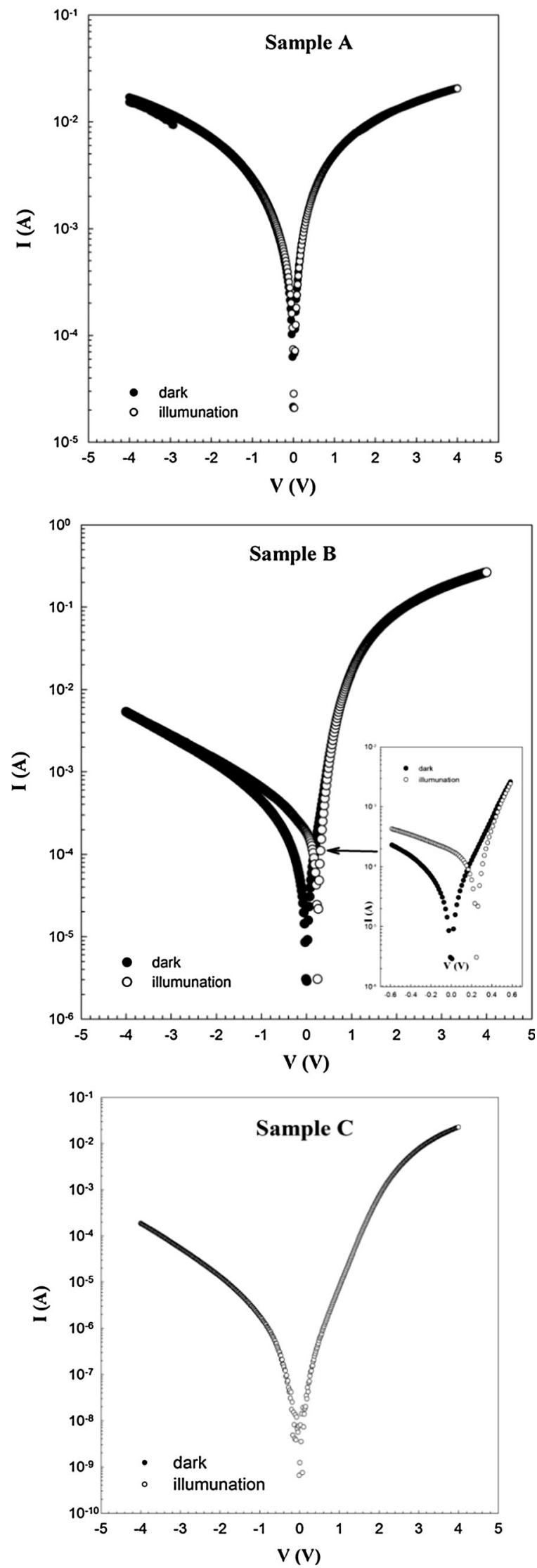

Fig. 7 Current-voltage measurements in the dark and illumination ambient 
of crystalline and surface morphology as shown in our experimental results.

Figure 5 shows PL emission spectrums of the samples A, $\mathrm{B}$ and $\mathrm{C}$ at different growth temperatures. From this figure, we clearly observed a blue shift in the peak of sample B (The peak wavelength and the FWHM of peak emission were 436 and $21.2 \mathrm{~nm}$, respectively). Similar results have been reported in the literature [21]. In the view of these results, these violet emissions of InGaN/GaN blue LEDs can be assumed to take place through recombination between the electrons injected into the conduction band and holes injected into the valence band of the InGaN active layer [22]. The major MQW emission band is located at 2.88, 2.84, $2.86 \mathrm{eV}$, respectively. In increasing temperatures, when the band gap energy first decreases and then increases, the FWHM of spectra shows a similar behaviour according to band gap values. These cases are in agreement with XRDoptimized result for sample B. PL results are consistent with similar studies of the literature [23].

Figure 6 shows FTIR results (energy position and FWHM) of $\operatorname{In}_{\mathrm{x}} \mathrm{Ga}_{(1-\mathrm{x})} \mathrm{N}$ for each of the three samples and their peak positions, and FWHM values are given in the last two columns of Table 3. Longitudinal-optical (LO) phonon vibration energy spectra of the $\operatorname{In}_{x} \mathrm{Ga}_{(1-\mathrm{x})} \mathrm{N}$ active layer was identified with ATR in the mid-IR region as depending on the increasing $x$ mole fraction [24]. By increasing the In content values for active $\operatorname{In}_{x} \mathrm{Ga}_{(1-x)} \mathrm{N}$ epitaxial layers, when the LO phonon vibration energy regularly increases, the FWHM of spectra first decreases and then increases, and this case supports XRD and PL results.

Figure 7 shows forward and reverse bias I-V characteristics of the samples A, B and C under dark and light condition of a $200 \mathrm{~mW} / \mathrm{cm}^{2}$ at room temperature. As illustrated on Fig. 7, sample B, among these structures, show sensitivity to light at forward bias voltage while the other two structures do not. In addition, for Sample A, B and $\mathrm{C}$, on-off ratios were found as $10^{3}, 10^{5}$ and $10^{7}$, respectively at room temperature. The experimental values of ideality factor were calculated in terms of the equations by using the relations in [24]. For Sample A, B and C, the $n$ values were found as $6.61,3.10$ and 4.58 , respectively at room temperature. Experimental results show that sample $\mathrm{B}$ has better LED characteristics compared to the other two structures. Based on these results obtained from sample B, we conclude that it would be possible to use this structure for device applications.

\section{Conclusion}

In this present study, $5 x\left(\operatorname{In}_{\mathrm{x}} \mathrm{Ga}_{1-\mathrm{x}} \mathrm{N} / \mathrm{GaN}\right)$ MQW LED structures with growth temperature and In content $(\mathrm{x})$ of $650{ }^{\circ} \mathrm{C}(10.87), 667{ }^{\circ} \mathrm{C}$ (9.01) and $700{ }^{\circ} \mathrm{C}$ (7.51) were grown on sapphire substrates by MOCVD. Mosaic parameters (such as lateral and vertical CLs, tilt and twist angles) and surface properties of the films, heterogeneous strain values, dislocation densities of the $\mathrm{GaN}$ and InGaN layers were studied using HRXRD, AFM, FTIR, PL and I-V measurements. HRXRD results show that lateral and vertical CLs, tilt and twist angles and heterogeneous strain values are affected by growth temperature and In contents in the active layers of LEDs. An optimized growth temperature for InGaN active layer was found with structural, optical and electrical properties, and AFM results indicate that surface morphologies of the films dependent on the In composition. Moreover, at this growth temperature, it was observed from AFM images that the grains on the morphological structure of the surface grew, and surface roughness increased as well. PL analysis indicated that forbidden band energy gap shifted to blue. It was also observed through $\mathrm{I}-\mathrm{V}$ analyses that measurements carried under light responded to optimized temperature. Furthermore, it was observed that while band gap increased for InGaN active layer, oscillation energy decreased. In conclusion, it was observed that structural, optical and electrical properties were consistent depending on temperature. It was revealed that structural defects obtained through reciprocal lattice space map by HRXRD are consistent with their optical and electrical results.

Acknowledgments This work is supported by the projects DPT2011K120290, ESF-EPIGRAT, EU-N4E, and NATO-SET-181, and TUBITAK under Project Nos. 107A004, 107A012, and 109E301.

\section{References}

1. S. Nakamura, Science 281, 956 (1998)

2. S. Chichibu, T. Azuhata, T. Sota, S. Nakamura, Appl. Phys. Lett. 69, 4188 (1996)

3. S.D. Lester, F.A. Ponce, M.G. Crawford, D.A. Steigerwald, Appl. Phys. Lett. 66, 1249 (1995)

4. D. Kapolnek, X.H. Wu, B. Heyıng, S. Keller, B.P. Keller, U.K. Mishra, S.P. Denbaars, J.S. Speck, Appl. Phys. Lett. 67, 1541 (1995)

5. M. Schuster, P.O. Gervais, B. Jobst, W. Hösler, R. Averbeck, H. Riechert, A. Iberlkand, R. Stömmerk, J. Phys. D Appl. Phys. 32, 56 (1999)

6. M.A. Moram, M.E. Vickers, Rep. Prog. Phys. 72, 036502 (2009)

7. M.K. Öztürk, H. Yu, B. Sarıkavak, S. Korçak, S. Özçelik, E. Özbay, J. Mater. Sci. Mater. Electron. 21, 185 (2010)

8. T. Metzger, R. Höpler, E. Born, O. Ambacher, M. Stutzmann, R. Stömmer, M. Schuster, H. Gobe, S. Christiansen, M. Albrecht, H.P. Strun, Philos. Mag. A 77, 1013 (1998)

9. G.K. Williamson, W.H. Hall, Acta Metall. 1, 22 (1953)

10. H. Yu, M.K. Öztürk, S. Özçelik, E. Özbay, J. Crys, Growth 293 , 273 (2006)

11. F.K. Yam, Z. Hassan, Superlattices Microstruct. 43, 1 (2008)

12. E. Arslan, M.K. Öztürk, Ö. Duygulu, A.A. Kaya, S. Özçelik, E. Özbay, Appl. Phys. Mater. Sci. Process. 94, 73 (2009)

13. E. Arslan, M.K. Öztürk, A. Teke, S. Özçelik, E. Özbay, J. Phys. D Appl. Phys. 41, 155317 (2008) 
14. M.E. Vickers, M.J. Kappers, R. Datta, C. McAleese, T.M. Smeeton, F.D.G. Rayment, C.J. Humphreys, J. Phys. D Appl. Phys. 38, A99 (2005)

15. X.H. Zheng, H. Chen, Z.B. Yan, Y.J. Han, H.B. Yu, D.S. Li, Q. Huang, J.M. Zhou, J. Cryst. Growth 255, 63 (2003)

16. P. Gay, P.B. Hirsch, A. Kelly, Acta Metall. 1, 315 (1953)

17. C.G. Dunn, E.F. Koch, Acta Metall. 5, 548 (1957)

18. P.F. Fewster, J. Appl. Crystallogr. 22, 64 (1989)

19. M.J. Hordon, B.L. Averbach, Acta Met. 9, 237 (1961)

20. Z.F. Ma, D.G. Zhao, Y.T. Wang, D.S. Jiang, S.M. Zhang, J.J. Zhu, Z.S. Liu, B.J. Sun, Hui Yang, J.W. Liang, J. Phys. D Appl. Phys. 41, 105106 (2008)
21. S.K. Leey, T.H. Kımy, S.Y. Leey, K.C. Choi, P. Yang, Philos. Mag. 87, 2105 (2007)

22. S. Nakamura, M. Senoh, T. Mukai, Appl. Phys. Lett. 62, 2390 (1993)

23. A. Chitnis, C. Chen, V. Adivarahan, M. Shatalov, E. Kuokstis, V. Mandavilli, J. Yang, M.A. Khan, Appl. Phys. Lett. 84, 183 (2004)

24. D. Coquillat, M.L. Vassor d'Yerville, M. Kazan, C. Liu, I.M. Watson, P.R. Edwards, R.W. Martin, H.M.H. Chong, R.M. De La Rue., J. Appl. Phys. 103, 44910 (2008)

25. B. Kınacı, S.Ş. Çetin, A. Bengi, S. Özçelik, Mater. Sci. Semicond. Process. 15, 531 (2012) 